\title{
DIAGNÓSTICO SOCIOECONÔMICO EM ÁREAS DE PEQUENOS PRODUTORES RURAIS NO ESTADO DE RORAIMA, BRASIL
}

\section{Social-Economic Diagnosis in Small Agricultural Producers Areas in the State of Roraima, Brazil}

\author{
Marcelo Francia Arco-Verde ${ }^{1}$ \\ Moisés Mourão Jr. ${ }^{2}$ \\ Carlos Eugênio Vitoriano Lopes ${ }^{3}$ \\ Fabrício Nunes de Freitas ${ }^{4}$
}

\section{Resumo}

O objetivo deste trabalho foi identificar e avaliar as características socioeconômicas das propriedades de pequenos produtores na região do Apiaú, município de Mucajaí, por meio da metodologia de D\&D, aplicando-se questionários aos produtores, com ênfase nas características sobre a família, propriedade rural e expectativas futuras, entrevistando produtores a respeito do modelo agroflorestal. Por meio de análise de freqüências de ocorrência única ou cruzada, os dados foram analisados e um perfil foi configurado. Ficou evidenciado que a adoção de inovações tecnológicas depende do nível de confiança e credibilidade dos produtores em relação à ação continua dos técnicos junto à comunidade avaliada.

Palavras-chave: Diagnóstico; Pesquisa Participativa; Agrofloresta; Roraima.

\section{Abstract}

The aim of this work was to identify and to analyze social economic characteristics from small holders in Apiaú region, municipality of Mucajaí. The researchers used D\&D methodology focusing information on family, rural property and future expectation, interviewing the producers about agroforestry model. Using frequency analysis with single or cross occurrence, the data had been analyzed and a profile was configured. It was evident that technology innovation adoption depends of trust, credibility and continuous visits in the community.

Keywords: Diagnoses; Rural Research; Agroforestry; Roraima.

\footnotetext{
${ }^{1}$ Eng.Florestal, M.Sc., pesquisador da Embrapa Roraima. arcoverd@cpafrr.embrapa.br End.: Caixa postal 133, CEP 69301-970. Boa Vista-RR. Tel/fax (95) 626-7125.

2 Biólogo, M.Sc., pesquisador da Embrapa Roraima.

${ }^{3}$ Eng. Agrônomo, técnico de nível superior da Embrapa Roraima.

${ }^{4}$ Eng. Agrônomo, técnico do Departamento do Meio Ambiente.
} 


\section{Introdução}

O estado de Roraima é apresentado como uma região de alta potencialidade agrícola, sendo definida como uma nova fronteira agrícola (MORALES, 2002). Entretanto, a dificuldade de abastecimento e a falência dos grandes projetos agropecuários da região indicam que os modelos de desenvolvimentos propostos para a agricultura são inadequados à realidade do estado (SARAGOUSSI, 1993).

A proposta de modelos agrícolas que contemplem os objetivos de uma produção suficiente, com custos sociais, econômicos e ecológicos sustentáveis, depende de um diagnóstico correto da realidade dos agricultores da região, decorrente do estudo e compreensão de seus sistemas de produção e modo de vida. A identificação da origem do produtor, o grau de organização da comunidade, problemas e êxitos encontrados nas propriedades são pontos importantes para a definição de estratégias em um trabalho participativo com comunidades de produtores rurais de uma determinada região.

O objetivo deste trabalho foi identificar as características socioeconômicas das propriedades rurais de pequenos produtores.

\section{Material e Métodos}

O estudo foi desenvolvido na colônia do Apiaú, Roraima, onde vivem 1200 famílias assentadas, localizada a $50 \mathrm{~km}$ da sede do município de Mucajaí. Essa região é de grande importância para o município, tanto em termos do número de famílias assentadas, quanto de produção (SEBRAE, 1998). Em 1999 foram selecionados 05 produtores rurais da Associação de Preservação Ambiental do Apiaú para iniciarem a implantação de sistemas agroflorestais em áreas de florestas alteradas, totalizando 12 produtores selecionados no ano de 2000.

O tamanho dos lotes está compreendido entre 15 e 60 hectares. Dentre as características edafoclimáticas dos lotes envolvidos no projeto, o clima da região está classificado como tropical úmido, do tipo Awi, com temperaturas médias anuais entre 28 e $38^{\circ} \mathrm{C}$, com período chuvoso de abril a agosto, com precipitação anual média de $2.000 \mathrm{~mm}$. Os solos apresentam pH médio de 4.8; textura areno-argilosa e ausência de pedregosidade.

Para definição dos perfis socioeconômicos foram utilizados questionários com ênfase em dados sobre a família, propriedade e expectativas dos produtores em relação ao projeto implantado. O preenchimento de cada questionário foi de aproximadamente duas horas e meia. Participaram da pesquisa 10 produtores rurais, onde o perfil de cada entrevistado foi classificado nas seguintes categorias: a) origem, b) faixa etária, c) tempo de permanência no lote, d) tempo de ocupação mensal do lote, e) composição familiar, f) tipo de mãode-obra utilizada, g) área cultivada, h) área com potencial para expansão dos plantios, i) área de preservação permanente, j) recursos hídricos e l) renda familiar. Os dados foram analisados a partir de tabelas de freqüência de ocorrência única ou cruzada, utilizando-se os softwares STATISTICA 5.5 e MVSP 2.0.

\section{Resultados e Discussão}

Observou-se que a maioria dos produtores é procedente do nordeste brasileiro, principalmente do estado do Maranhão (Figura 1) e a faixa etária está situada entre 37 a 62 anos e média de 49,5 anos. Os fluxos migratórios indicam, na maioria dos casos, uma permanência temporária em outro estado, seguida por uma migração para 0 estado de Roraima (Figura 1). 


\section{Figura 1 - Fluxos de migração dos produtores assistidos no projeto Apiaú, Roraima.}

Figure 1 - Flows of migration of the produœrs attended in the project Apiaú, Roraima.

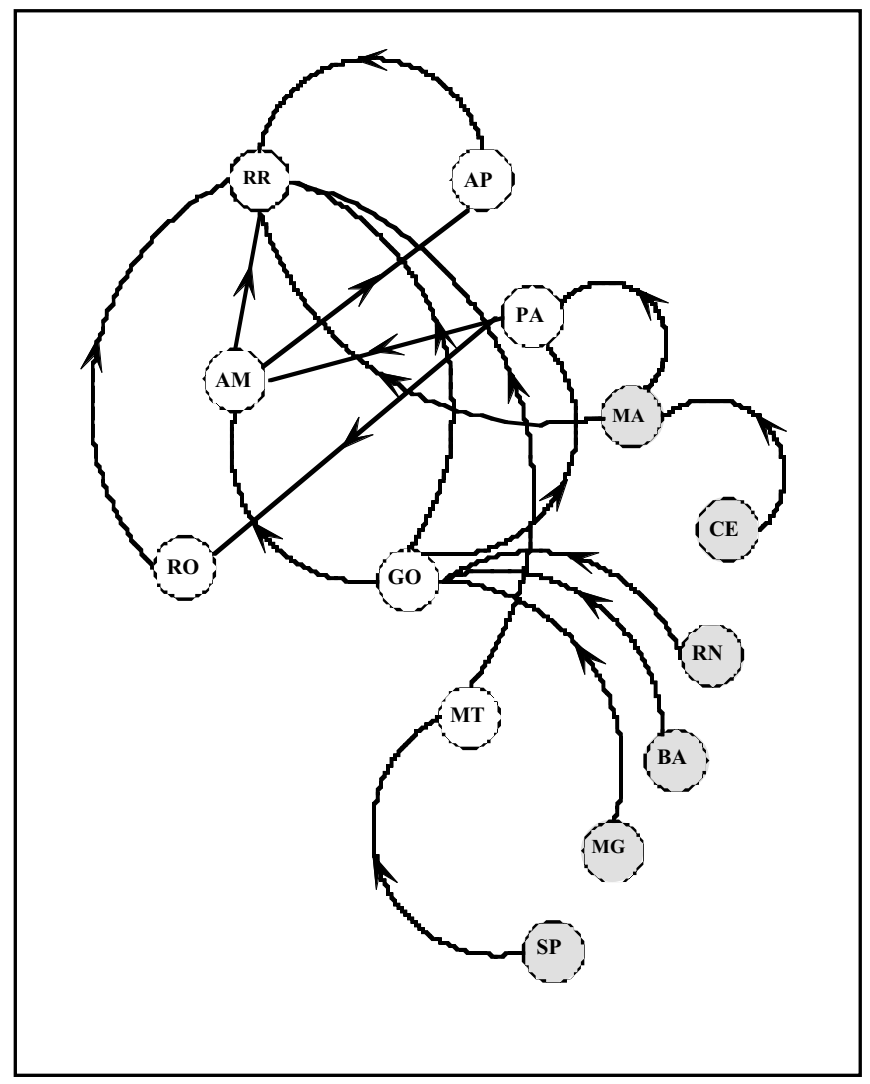

Em cada família, o número médio de filhos foi 3,3, com máximo de 8, com faixa etánia entre 15 e 25 anos, o que permite a participação deles como mão-de-obra familiar.

As famílias ocupam os lotes em um período que varia de 2 a 11 anos. No caso das famílias que se estabeleceram na região mais recentemente, entre 2 e 4 anos, há uma grande probabilidade de nova migração. Devido às dificuldades de comercialização de seus produtos na região, os produtores necessitam viajar aproximadamente $100 \mathrm{~km}$ até a capital do estado, Boa Vista, para vender seus produtos, exigindo das famílias a permanência de aproximadamente $25 \%$ do tempo ausentes de suas propriedades.

Os sistemas de produção ocupam de 3 a 30 hectares do total da área, em média 9,3 hectares. Devido ao baixo índice de desmatamento das propriedades, onde as áreas de preservação permanente continuam intocadas, há a possibilidade de expandir os plantios de 2 a 10 hectares em cada lote, com interesse em implantar espécies perenes como açaí, pupunha e cupuaçu.
Geralmente a mão-de-obra utilizada é familiar, constituída pelo pai, mãe, filhos e agregados. Eventualmente ocorre o mutirão entre os produtores, nos períodos de preparo do solo, plantio, conservação e colheita onde há maior necessidade de mão-de-obra.

Os recursos hídricos naturais existentes nas propriedades geralmente são os igarapés e as cachoeiras, com os quais se constrói reservatórios de água e açudes utilizados para o consumo familiar, irrigação e manutenção de pequenos animais. A maior parte dos recursos hídricos existentes na região é temporária, sendo utilizáveis durante oito meses do ano.

Com relação à adoção de tecnologia propostas pela equipe, os produtores que as acataram apresentaram maior renda mensal $(p<0,05)$ $[R \$ 200,00]$, do que os produtores mais reticentes à sua adoção [R\$110,00] (Figura 2). Uma ressalva é feita ao fato de que a aceitabilidade pela adoção de nova tecnologia pelos produtores foi fortemente influenciada pela credibilidade e confiança na equipe de trabalho, devido especialmente à maior constância da assistência a eles disponibilizada. 


\section{Figura 2 - Valores médios e intervalo de confiança para a renda familiar mensal, em fun-} ção do grau de adoção tecnológica.

Figure 2 - Average values and reliable interval for the monthly familiar income, in function of the degree of technological adoption.

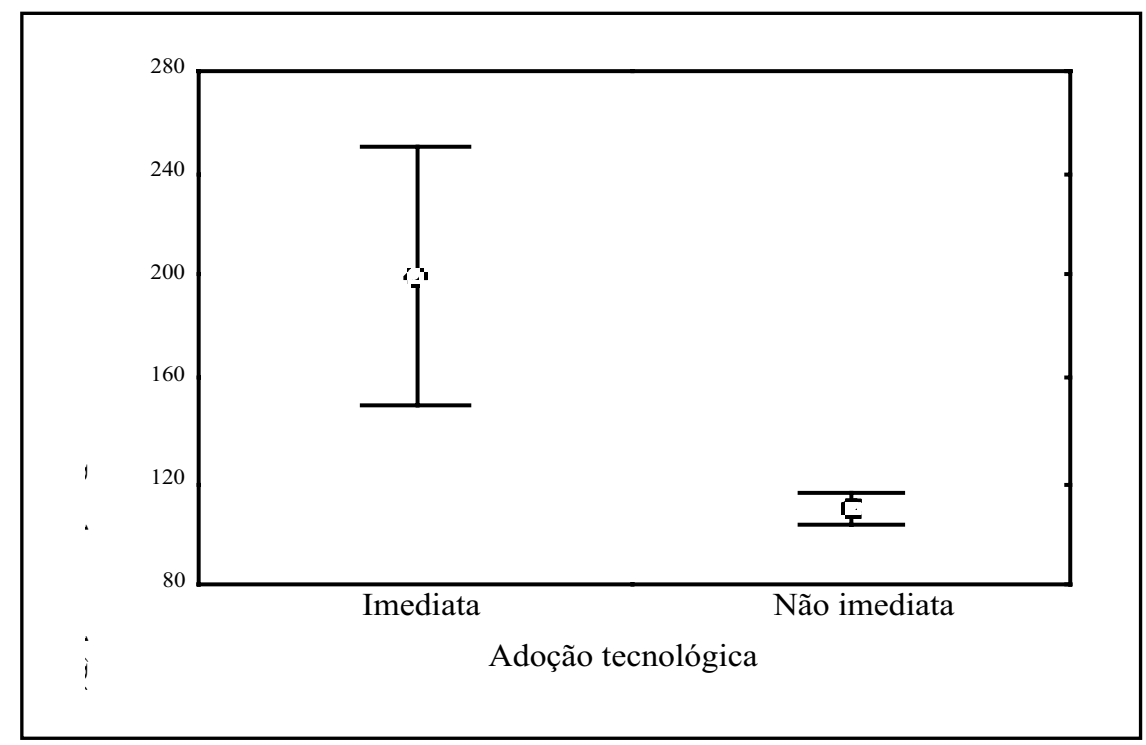

\section{Conclusões}

Desenvolver trabalhos com sistemas agroflorestais em propriedades rurais demanda selecionar produtores que trabalhem em associação rural organizada, por meio de aplicação de diagnósticos que informem adequadamente os diferentes nichos existentes na comunidade. Dessa forma, inicia-se o processo de aplicação da metodologia para a implantação e capacitação de sistemas agroflorestais, buscando acompanhar efetivamente as atividades desenvolvidas em conjunto com o grupo. Com isso, espera-se que a implantação de sistemas agroflorestais promova uma maior diversificação da renda, otimização do uso da mão-deobra familiar e diminuição do êxodo rural.

\section{Referências}

MORALES, E.A.V. Especial Roraima: Sol, sonhos e coragem. Revista Panorama Rural, São Paulo, v. 3, n. 35, p. 52-65. 2002.

SARAGOUSSI, M. Pequenos Produtores Rurais de Terra-Firme em Três Localidades do Estado do Amazonas: Principais Problemas; Propostas de Soluções. In: SARAGOUSSI, M.; FERREIRA E. J. G.; SANTOS. G. M.; LEÃO, E. M.; OLIVEIRA, L A. (Ed.s). Bases Cientificas para Estratégias de Preservação e Desenvolvimento da Amazônia. Manaus: Instituto Nacional da Amazônia, 1993. v. 2. p. 107.

SEBRAE/RR. Diagnóstico Sócio-Econômico de Mucajaí: SEBRAE/RR. 2 ed. Boa Vista: SEBRAE/RR 1998. p. 52. 